\title{
Prospects of fish supply-demand and its implications for food and nutrition security in Egypt
}

\author{
Nhuong Tran ${ }^{\mathrm{a}, *}$, Long Chu ${ }^{\mathrm{b}}$, Chin Yee Chan ${ }^{\mathrm{a}}$, Jeffrey Peart ${ }^{\mathrm{a}}$, Ahmed M. Nasr-Allah ${ }^{\mathrm{c}}$, \\ Harrison Charo-Karisa ${ }^{c, d}$ \\ ${ }^{\text {a } W o r l d F i s h, ~ P e n a n g, ~ M a l a y s i a ~}$ \\ ${ }^{\mathrm{b}}$ Crawford School of Public Policy, The Australian National University, Canberra, Australia \\ ${ }^{\mathrm{c}}$ WorldFish Egypt, Cairo, Egypt \\ ${ }^{\mathrm{d}}$ The World Bank, Washington, DC, USA
}

\section{A R T I C L E I N F O}

\section{Keywords:}

Aquaculture

Feed

Fisheries

Infectious disease

Seed

Tax

Water

\begin{abstract}
A B S T R A C T
Aquaculture plays an increasingly important role in meeting the rising global demand for fish fuelled by economic and demographic growth. However, in many middle-income countries, aquaculture is constrained by rising labour costs, limited input supply, environmental concerns, and infectious diseases. In this paper, we developed a multi-species, multi-sector equilibrium model and applied it to the fishery sector of Egypt, a leading aquaculture producer in Africa, to examine these barriers. Projection results show that rising wage rates would slow down the growth of labour-intensive aquaculture compared to those that use relatively less labour. The demand for feed, seed inputs and water use for aquaculture would substantially increase. The results also show that disease outbreaks would possibly affect production sectors via output reduction and also consumers via increases in fish price. Our findings suggest that stabilising the prices of feed and seed, investments in disease control and input-use efficiency improvement technologies, including water use, are important while the overall effectiveness of tax instruments is modest. Though calibrated to Egypt, our approach can be applied to other middle-size national aquaculture industries.
\end{abstract}

\section{Introduction}

The contribution of fish and other aquatic foods to nutrition security, income and employment generation is crucial in many low and middleincome countries [11]. Fish and other aquatic foods have high concentrations of essential micronutrient, which can potentially address a number of micronutrient deficiencies present in developing countries [3, 42]. In many African countries with less advantaged economic development relative to the rest of the world, fish is an ever more important source of protein and micronutrients because it is more affordable than other land-based animal-source foods $[4,34]$. For this reason, more than $30 \%$ of Africa's population consumes fish as their primary source of animal-source foods [34]. Fisheries and aquaculture sectors provide incomes and employment for millions of women and men in developing countries [11]. The rapid growth of aquaculture, for example, benefits the moderate and extreme poor in rural areas in Bangladesh by reducing fish prices, thus increasing consumption among these groups [43].

Global demand for fish and other aquatic foods is expected to double by 2050 [33], fuelled by population and economic growth, globalisation, urbanisation in developing countries, and diet shifts in developed countries [11]. While fast-growing demands are opportunities for aquaculture expansion in low and middle-income countries, challenges also exist, such as rising costs of input supply and quality $[20,25]$, infectious diseases $[22,26,27]$, and rising labour costs that can reduce the growth momentum in economic sectors $[1,17]$. As a result, it is important to recognise and anticipate these challenges to identify response policies, development interventions, and investments to sustain future fish supply growth. These developments are vital to meeting the increasing demand while addressing negative socio-economic and environmental impacts at the same time. In this paper, we formalise a partial-equilibrium model to examine fish supply and demand trends in Egypt, a middle-income country and a major aquaculture producer in Africa, to explore policy implications and lessons applicable to future aquaculture development in Egypt and other developing countries.

Fish is an important component of the traditional diet in Egypt [7,8, $30]$. At over $20 \mathrm{~kg}$ per person per year in 2020, Egypt's per-capita fish

\footnotetext{
* Corresponding author.

E-mail address: n.tran@cgiar.org (N. Tran).
} 
consumption is marginally below that of much wealthier European countries, where income is approximately ten times higher. Fish provides $38 \%$ of the total animal protein for Egyptian people [32] and sources of micronutrients, which are vital for health, especially for mothers in the first 100 days of pregnancy and infants in the first 1000 days of infancy [30]. Thus, the fishery sector plays a significant role in achieving the national food security objectives, especially when the malnutrition rate in the country is relatively high [47].

The Egyptian aquaculture sector is the most developed in Africa and the Middle East. Egyptian aquaculture production is concentrated around the Northern Lakes in the Nile delta region [31]. Open-pond culture systems produced around $87 \%$ of farm production in 2018 (GAFRD, 2019). Nile tilapia (Oreochromis niloticus) is the main cultured fish species, accounting for $66 \%$ of farmed fish production in Egypt in 2019. Other important farmed fish in Egypt include mullet, carp, seabass, and seabream. The proliferation of aquaculture in Egypt has high socio-economic benefits [32].

Fish consumption in Egypt has rapidly increased over the last 20 years, nearly doubling from $11.3 \mathrm{~kg} /$ per/year in 2001 to $20.26 \mathrm{~kg} / \mathrm{per} /$ year in 2020, exceeding beef and poultry consumption [30]. To meet the increasing demand, the domestic production of fish in Egypt has grown noticeably from 0.7 million tons in 2000 to more than 2 million tons in 2019 [14]. Most of the increases in fish production are attributed to aquaculture, as official statistics indicate that wild catch rates reached the maximum sustainable yield around the year 2000, after which yields have plateaued $[13,16]$. As a result, aquaculture now contributes $80 \%$ to the total domestic fish supply. The extreme growth of aquaculture in Egypt has led to the country being among the top 10 producers of farmed fish in the world [10]. However, the demand for fish still necessitates the importation of around 324 thousand tons of fish annually [15] approximately $20-25 \%$ of the total fish consumption, which emphasises the importance of sustainable growth of fish production in the country.

Fish production in Egypt faces several constraints that require effective management and mitigation. Capture fisheries have been negatively affected by overfishing and pollution, leading the productivity of the sector to stagnate, even decline, in recent years $[38,40]$. In freshwater aquaculture, water availability and quality have recently become a constraint, mainly due to scarcity amidst increased demand for crop production $[28,41]$. Furthermore, the cost of other aquaculture inputs, such as feed, seed, and labour, is rapidly rising. In addition, aquaculture is also affected by the proliferation of disease outbreaks with severe impacts on production [41]. This problem is exacerbated when fish farmers do not always follow biosecurity practices due to inconsistent policy and controls [23]. These issues, especially those pertaining to aquaculture, require the immediate attention of policymakers since doing so is necessary for sustainable intensification of production and achieving Egypt's food security objectives.

This paper formalises a multi-species, multi-sector equilibrium model to compare a baseline with possible alternative scenarios for the Egyptian fisheries sector. These scenarios are grouped into two main categories, centred on aquaculture inputs and outputs because the driving force behind Egypt's capture fisheries has been stable for the past 20 years. In the first category (aquaculture inputs), we analyse two scenarios where increases in aquaculture inputs (feed, seed, and water) affect the profitability of the production sector. In the second category, we expand our analysis to incorporate possible changes in taxes and the consequences of disease outbreaks in fish farms. By comparing the projection outcomes in these four scenarios, we highlight future threats to Egypt's fish supply, in a bid to guide the evolution and transformation of aquatic foods into more efficient and resilient systems.

\section{Material and methods}

This section describes the data and delineates the model specification to analyse the Egyptian fish sector. In the literature, there are a number of models that have been developed to simulate fish supply and demand, e.g., the fish IMPACT model of the World Bank $[24,46]$ and the Aglink-Cosimo model [9] - both used to project the global fisheries sector in the medium term. With a focus on the global scale, these models often work at a very high level of aggregation. Other developed models, e.g. the ASIA-FISH model ([6]; [44]) could provide more disaggregated projection, but they require a large number of parameters to be estimated from real-life data using econometric techniques. This requirement is not possible in the case of Egypt due to the lack of reliable data. Disaggregated fisheries sector data often exhibit inconsistencies if double-checked from various sources, though aggregate data existed for up to 40 years in Egypt.

To overcome this challenge, our approach was to develop a simulation model which minimizes the level of data-demanding while maintaining the key objective of being able to analyse the key scenarios and evaluate policy impacts. The approach has been successfully applied to investigate fish supply and demand and its implications for food security in Zambia [45]. In this approach, we limited the analysis to main fish species groups and production types, collected the best reliable information, and then adjusted the modelling specification to fit what was available. Fortunately, we were able to collaborate with the General Authority for Fish Resources Development (GAFRD) in Egypt to collect and compare data from various sources, cross-check and adjust to eliminate inconsistencies. As a result, we managed to have consistent data for year 2016, which covers five key fish species, each of which can possibly be produced with different types of aquaculture production, or naturally caught in four fishing sites in Egypt. The data will be described in detail below. More disaggregated or longer data series were unreliable or not available.

\subsection{Data}

The production data for 2016 are presented in Table 1. They cover five fish groups that are referred to by their local names, i.e., Tilapia (Oreochromis spp.), Mullet species (Mugil cephalus and Liza ramada), catfish (Clarias spp.), carp (Cyprinus carpio) and other fish. Throughout this paper, we use a five-element set to refer to the fish groups, i.e., $S=$ [Tilapia, Mullet, Catfish, Carp, Other fish].

Fish can be produced from either aquaculture or capture fisheries (wild-catch). Aquaculture in Egypt is further classified into four types following the description of Shaalan et al. [39], namely semi-intensive farming (Semi-Intensive), cages (Cage), fish farming in rice-fields (Rice-fish systems or rice-fish polyculture), and Intensive farming (Intensive). Wild catch includes four fishing sites, namely the Mediterranean Sea (MedSed), the Red Sea (RedSea), the Nile River (Nile), and inland lakes (Lakes). In total, there are eight production categories, and we use an eight-element set to refer to the production categories, i.e., $P C=[$ Cage, Ricefields, Intensive, Semi - Intensive, Nile, RedSea, MedSea, Lakes]. The first four elements are aquaculture types, and the last four elements are wild-catch.

Combining the eight production categories and the five species gives 40 possible combinations of category-species groups. Each of these 40 combinations is termed a 'sector'. Not all sectors are active, or in other words, not all species are produced in all production categories. In fact, there are only 30 active sectors (so Table 1 has 30 data rows). To distinguish active and non-active sectors, 40 binary variables $\nu(P C, S)$ were used, one for each sector, to indicate whether the sector is active (value 1 ) or inactive (value 0 ).

The production sectors use different sets of inputs. For example, the aquaculture sectors might possibly use six types of inputs, namely labour, fuel, seed, feed, fresh water, and others. Wild-catch sectors only use three types of inputs labour, fuel, and others. Thus, the data for seed, feed and fresh water in the wild-catch sectors are empty.

Table 2 shows fish consumption, export and import for 2016, one row for each of the five species groups. Fish consumers can consume domestic and imported fish and fish products. Domestic products can also be consumed locally or exported. Data in Tables 1 and 2 have been 
Table 1

Fish production in Egypt (2016).

\begin{tabular}{|c|c|c|c|c|c|c|c|c|c|c|}
\hline & \multirow[t]{2}{*}{ Sector } & \multirow[t]{2}{*}{ Species } & \multicolumn{2}{|l|}{ Output } & \multicolumn{6}{|c|}{ Input cost/requirement } \\
\hline & & & Quantity & Value & Labour & Fuel & Seed & Feed & Water & Other \\
\hline \multirow[t]{16}{*}{ AQUACULTURE } & \multirow[t]{4}{*}{ Cages } & Tilapia & 75.0 & 1.6 & 13.7 & $<0.1$ & $<0.1$ & 72.0 & & 6.0 \\
\hline & & Mullet & 6.3 & 2.3 & 1.1 & $<0.1$ & $<0.1$ & 6.5 & & 0.5 \\
\hline & & Carp & 94.2 & 1.0 & 17.1 & $<0.1$ & $<0.1$ & $<0.1$ & & 7.5 \\
\hline & & Others & 0.2 & 2.7 & $<0.1$ & $<0.1$ & $<0.1$ & 0.2 & & $<0.1$ \\
\hline & \multirow[t]{3}{*}{ Rice-Fish systems } & Tilapia & 4.1 & 3.6 & 1.7 & $<0.1$ & 0.7 & $<0.1$ & & 0.4 \\
\hline & & Catfish & 2.7 & 3.5 & 1.1 & $<0.1$ & 0.5 & $<0.1$ & & 0.2 \\
\hline & & Carp & 6.8 & 6.6 & 2.8 & $<0.1$ & 1.4 & $<0.1$ & & 0.6 \\
\hline & \multirow[t]{4}{*}{ Intensive } & Tilapia & 2.1 & 3.2 & $<0.1$ & 0.1 & 0.2 & 1.8 & 11.6 & 0.1 \\
\hline & & Mullet & $<0.1$ & 0.1 & $<0.1$ & $<0.1$ & 0.0 & $<0.1$ & 0.3 & $<0.1$ \\
\hline & & Catfish & 4.9 & 6.2 & $<0.1$ & 0.2 & 0.5 & 4.1 & 26.2 & 0.2 \\
\hline & & Others & $<0.1$ & 0.1 & $<0.1$ & $<0.1$ & $<0.1$ & $<0.1$ & 0.1 & $<0.1$ \\
\hline & \multirow[t]{5}{*}{ Semi - intensive } & Tilapia & 859.1 & 1263.7 & 7.5 & 32.2 & 85.1 & 719.5 & 4639.2 & 43.0 \\
\hline & & Mullet & 147.5 & 339.3 & 1.3 & 5.5 & 14.6 & 123.5 & 796.4 & 7.4 \\
\hline & & Catfish & 0.1 & 0.1 & $<0.1$ & $<0.1$ & $<0.1$ & 0.1 & 0.4 & $<0.1$ \\
\hline & & Carp & 100.0 & 196.0 & 0.9 & 3.7 & 9.9 & 83.7 & 539.9 & 5.0 \\
\hline & & Others & 67.8 & 271.2 & 0.6 & 2.5 & 6.7 & 56.8 & 366.2 & 3.4 \\
\hline \multirow[t]{14}{*}{ WILD CATCH } & \multirow[t]{5}{*}{ NileRiver } & Tilapia & 23.1 & 34.0 & 11.2 & 0.7 & & & & 2.1 \\
\hline & & Mullet & 0.5 & 1.4 & 0.2 & $<0.1$ & & & & $<0.1$ \\
\hline & & Catfish & 14.3 & 18.2 & 6.9 & 1.1 & & & & 1.3 \\
\hline & & Carp & 10.3 & 20.3 & 5.0 & 0.3 & & & & 0.9 \\
\hline & & Others & 25.2 & 67.0 & 12.3 & 2.0 & & & & 2.3 \\
\hline & \multirow[t]{2}{*}{ RedSea } & Mullet & 0.2 & 0.4 & 0.1 & $<0.1$ & & & & $<0.1$ \\
\hline & & Others & 49.5 & 131.6 & 24.1 & 4.5 & & & & 4.5 \\
\hline & \multirow[t]{2}{*}{ MedSea } & Mullet & 1.8 & 4.9 & 0.9 & 0.1 & & & & 0.2 \\
\hline & & Others & 52.2 & 138.7 & 25.4 & 4.7 & & & & 4.7 \\
\hline & \multirow[t]{5}{*}{ Lakes } & Tilapia & 84.8 & 124.8 & 41.2 & 2.6 & & & & 7.6 \\
\hline & & Mullet & 26.8 & 74.0 & 13.0 & 0.8 & & & & 2.4 \\
\hline & & Catfish & 14.6 & 18.6 & 7.1 & 1.2 & & & & 1.3 \\
\hline & & Carp & 5.9 & 11.5 & 2.9 & 0.2 & & & & 0.5 \\
\hline & & Others & 27.2 & 54.4 & 13.2 & 2.4 & & & & 2.4 \\
\hline
\end{tabular}

*** i Unit: Fish quantity is measured in 1000 tons; fresh water is measured in mega litters; other variables in millions USD; all rounded to the nearest single digit numbers.

Table 2

Fish consumption and international trade in Egypt (2016).

\begin{tabular}{|c|c|c|c|c|c|c|}
\hline \multirow[t]{2}{*}{ Species } & \multicolumn{2}{|c|}{ Consumption } & \multicolumn{2}{|l|}{ Import } & \multicolumn{2}{|l|}{ Export } \\
\hline & Quantity & Value & Quantity & Value & Quantity & Value \\
\hline Tilapia & 1041.3 & 2144.4 & 0.5 & 1.0 & 7.0 & 10.6 \\
\hline Mullet & 183.0 & 589.4 & 0.0 & 0.0 & 0.0 & 0.0 \\
\hline Catfish & 36.5 & 69.8 & 0.0 & 0.0 & 0.0 & 0.0 \\
\hline Carp & 211.1 & 538.2 & 0.0 & 0.0 & 6.0 & 12.8 \\
\hline
\end{tabular}

$* * *$ ii Unit: Fish quantity is measured in 1000 tons; other variables in millions USD; all rounded to the nearest single digit numbers.

cross-checked to ensure consistencies, i.e., the sum of domestic production and import equals the sum of consumption and export.

\subsection{Model specification}

Our model in this paper is built to best fit the reliable data as explained in the previous section with the base year 2016. Following the earlier frameworks of Dey et al. [6] and Rosegrant \& Team [37], we formalise a multi-species-multi-sector equilibrium feature that characterises the equilibrium of supply and demand in all related markets. For each of five species that any of eight production types can possibly produce, our mathematical model formalises two fundamental principles, namely: (i) increases in the demand for fish (domestic consumption plus export, if any) are equal to increases in supply (domestic production plus import, if any) and (ii) fish consumption would reduce when prices increase, and fish production would increase if profitability rises. Thus, our model can project the outcome in Egypt's fish sector at a species disaggregation level.

In developing the model, we adopt a number of modifications in the model structure to enhance its practicality and applicability given the available data and information. On the supply side in particular, while the ASIA-FISH model specifies fish supply functions by combining the Hotelling's lemma and the estimate of profit function ([6], see Eq. (2)), our model specifies how fish supply responds to profit, similar to the global IMPACT model, to best fit with the data availability. On the consumption side, we also apply a slightly different modelling approach to fit with the data. Here, on the one hand, the IMPACT model specifies iso-elasticity demand functions [36] - a simplistic version of what is suggested by consumer theory; and on the other, the ASIA-FISH model uses the AIDS-style demand functions, which is consistent with the consumer theory but data-demanding. As a compromise, we specify consumer preference in a basic functional form that is consistent with theory and derive the Marshallian demand for each fish species group. With this approach, we can minimize the need for borrowing too many parameters from literature where most of them were not estimated for Egypt.

\subsubsection{Production and production inputs}

As described in Section 3.1, there are 40 production sectors, but only 30 are active. The outputs of inactive sectors are zero, and this is formalized in Eq. (1) where $q_{t}(P C, S)$ is the output of each species in each production category at time $t$.

$q_{t}(P C, S)=0 \operatorname{if} \nu(P C, S)=0$

For declaring inputs, a six-element set $C I=[$ Labour, Fuel, Seed,Feed, Water, Other] was denoted for the inputs and $X_{t}(P C, S, C I)$ for the quantity of each input used in each sector at time $t$. These quantities are zero if the inputs are not used or the sector is not active. The input demands of the active sectors are presented in Eq. (2) where $A_{t}^{x}(P C, S, C I)$ is the input required to produce one unit of output, which varies across species and production sector. From here, when a complete description of a set has been defined, the shortcut (.) is used for compactness, unless when purposely avoiding possible confusion. 


$$
X_{t}(P C, S, C I)=q_{t}(P C, S) \times \quad A_{t}^{x}(P C, S, C I)
$$

Following the World Bank's IMPACT model [36], the fish supply in each active sector is determined in Eq. (3) which specifies that the supply will respond to the rate of return in fishing.

$q_{t}(P C, S)=A^{q}(P C, S) \times\left(\frac{\Pi_{t}(P C, S)}{\Pi_{\text {base }}(P C, S)}\right)^{\epsilon^{q}(P C, S)}$

where $\Pi_{t}()=\frac{p_{t}^{f}(P C, S) q_{t}(P C, S)}{\sum_{C l} w_{t}(C I) X_{t}(P C, S, C I)}$ is the rate of return (benefit over cost) at time $\mathrm{t} ; p_{t}^{f}($.$) is the farm-gate price of fish which could possibly vary$ across different types of production, $w_{t}($.$) is the price of inputs; \epsilon^{q}($.$) is$ the response elasticity of supply to the rate of return, and $A^{q}(P C, S)$ is a shift parameter.

\subsubsection{Fish consumption demand}

To model the demand for fish, we use a double-layer structure for a representative consumer in this study. Here consumers decide the quantity of each good in order to maximize the utility with a certain budget, e.g., how much to spend on each species and then within each species how much to spend on a domestic and imported product if any [6]. Both layers can be modelled using the Armington preference [2], which allows for a certain level of substitutability, e.g., when a product becomes more expensive, the consumer might substitute it with similar products. Compared to the iso-elasticity specified by the World Bank's IMPACT model, this approach is less mathematically tractable, but it is consistent with consumer theory such as the Engle and Cournot aggregation properties.

The double-layer optimization for the consumer decision is presented in Eqs. (4) and (5). Here, $e_{t}^{c}($.$) is a 5-element vector of the$ spending on each species (both domestic and imported if any) at time $t$; $y_{t}=y_{\text {base }}\left(1+g^{y}\right)^{t-b a s e}$ is the per-capita spending on fish at time $t$, which grows at an annual rate $g^{y} ; \sigma^{c}$ is a scalar constant-elasticity-ofsubstitution coefficient (CES); $Q_{t}^{d}($.$) and Q_{t}^{i}()$ are the consumption quantities of domestic and imported fish by a representative consumer respectively; $p_{t}^{d}($.$) and p_{t}^{i}($.$) are the prices paid by consumers for do-$ mestic and imported fish; $\sigma(S)$ is a vector of five CES coefficients, one for each species group; $A^{d}(S), A^{i}(S)$, and $A^{c}$ are vectors of coefficients which can, without the loss of generality, be normalized such that $A^{d}(S)+A^{i}(S)$ $=1$ and $\sum_{S} A^{c}()=1$.

$\max _{e_{t}^{c}(S)}\left[\sum_{S} A^{c}() e_{t}^{c}()^{1-\frac{1}{\sigma^{c}}}\right]^{\frac{\sigma^{c}}{1-\sigma^{c}}}$ subject to $\sum_{S} e_{t}^{c}=y_{t}$

$\max _{q_{t}^{d}(S) q_{t}^{i}(S)}\left[A^{d}(S) Q_{t}^{d}(S)^{1-\frac{1}{\sigma(s)}}+A^{i}(S) Q_{t}^{i}(s)^{1-\frac{1}{\sigma(s)}}\right]^{\frac{\sigma(S)}{1-\sigma(S)}} \quad$ subject to $p_{t}^{d}() Q_{t}^{d}()+.p_{t}^{i}() Q_{t}^{i}()$

$=e_{t}^{c}($.

Solving the optimization in Eqs. (4) and (5) is a straightforward calculus exercise though a little lengthy. The demand for domestically produced and imported fish by a representative consumer can be derived as in Eq. (6).

$Q_{t}^{\mu}()=e_{t}^{c} \frac{\left(\frac{A^{\mu(0}}{p_{t}^{\mu}()}\right)^{\sigma()}}{\sum_{\theta \in[d, i]} p_{t}^{\theta}(.)\left(\frac{A^{\theta 0}}{p_{t}^{\theta}()}\right)^{\sigma()}}$ for $\mu=[d, i]$

where $e_{t}^{c}()=y_{t} \frac{p_{t}^{c}(S)\left(\frac{A^{c}(S)}{p_{t}^{c}(s)}\right)^{\sigma(S)}}{\sum_{S} p_{t}^{c}(S)\left(\frac{A^{c}(S)}{p_{t}^{c}(s)}\right)^{\sigma(S)}}$ with $p_{t}^{c}(S)=\left[\sum_{\theta \in[d, i]} p_{t}^{\theta}(.)\left(\frac{A^{\theta \theta}}{p_{t}^{\theta}()}\right)^{\sigma()}\right]^{\frac{1}{1-\sigma(\cdot)}}$.

The market demand for domestic and imported fish, $q_{t}^{d}(S)$ and $q_{t}^{d}(S)$, can be formalized as in equation (7).
$q_{t}^{\mu}()=N_{t} Q_{t}^{\mu}()$ for $\mu=[d, i]$

where $N_{t}=N_{\text {base }}\left(1+g^{n}\right)^{\mathrm{t}-\text { base }}$ is the population at time $t$ that grows at an annual rate of $g^{n}$.

\subsubsection{Fish Export}

The demand for fish export is specified with a constant elasticity function in Eq. (8):

$q_{t}^{e x}(S)=Z_{t}^{e x}(S) \times\left(\frac{p_{t}^{e x}(S)}{p_{t}^{w}(S)}\right)^{\epsilon^{e x}(s)}$

where $q_{t}^{e x}($.$) is the export quantity of the species (if any) at time t;$ $\epsilon^{e x}(S) \leq 0$ is the elasticity coefficients for export demand showing how export quantity responds to the ratio between domestic and the world price; and $Z_{t}^{e x}(S)$ represents the vector of price-shift coefficients.

\subsubsection{Fish price formation and market clearing condition}

We denote $M_{t}^{d}()$ and $T_{t}^{d}()$ as the domestic margin and sale-tax rates. Using this notation, the consumer price of domestic fish can be calculated by incorporating the domestic margin and the sale-tax rate into the average farm-gate price as in Eq. (9).

$p_{t}^{d}(S)=\frac{\sum_{P C} p_{t}^{f}(P C, S) q_{t}(P C, S)}{\sum_{P C} q_{t}(P C, S)}\left(1+M_{t}^{d}(S)\right)\left(1+T_{t}^{d}(S)\right)$

The consumer price of imported fish equals the world (CIF) price plus import tax (if any) as presented in Eq. (10) where $p_{t}^{w}(S)$ is the world price, and $T_{t}^{i}(S)$ is the import tax rate.

$p_{t}^{i}(S)=p_{t}^{w}(S)\left(1+T_{t}^{i}(S)\right)$

The export price of fish equals the farm gate price plus export margin and export tax (if any) as presented in Eq. (11) where $M_{t}^{\text {ex }}(S)$ and $T_{t}^{e x}(S)$ are the export margin and export-tax rates.

$p_{t}^{e x}(S)=p_{t}^{f}(S)\left(1+M_{t}^{e x}(S)\right)\left(1+T_{t}^{e x}(S)\right)$

The market clearing condition requires the total (domestic) supply from all production sectors be equal to the consumption demand for domestic fish plus export as in Eq. (12).

$\sum_{P C} q_{t}(P C, S)=q_{t}^{d}(S)+q_{t}^{e x}(S)$

\subsection{Model calibration}

We calibrate the multi-species-multi-sector equilibrium model in specified Section 3.2 following the process described by Dawkins et al. [5]. On the production side, the coefficients $A_{t}^{x}(P C, S, C I)$ and $A^{q}(P C, S)$ in Eqs. (2) and (3) are calibrated by combining the data in Table 1 and the elasticity of supply with respect to the rate of return $\epsilon^{q}(P C, S)$ which is taken from the database of the World Bank's model. During the calibration of the production side, wild-catch outputs are assumed to be stable as it is a general opinion that most marine and inland fisheries resources in Egypt are fully or close to fully exploited [12].

We also calibrate the demand side of the model in a similar way. The parameters in the double-layer preference structure in Eqs. (4) and (5) and the export price-shift parameters in Eq. (8) are calculated by combining the data in Table 2 with the CES coefficients $\sigma^{C}, \sigma(S)$ and $\epsilon^{e x}(S)$. These coefficients are fine-tuned to best fit with the own-price elasticity values in the World Bank's database. The value for domestic and export margins in Eqs. (9) and (11) is calculated directly from the data in Tables 1 and 2.

The model will project the outcome of Egypt's fishery sector until 2030. To calibrate the inter-temporal developments of the fish market, 
the annual dynamics of population and per-capita income are incorporated into the model. It is assumed that Egypt population would increase by $1.95 \%$ a year $\left(g^{n}=0.0195\right)$, and the per-capita income would increase by $2.38 \%$ a year, which are the 30-year average between 1987 and 2016 (GAFRD statistics and World Bank database). In regard to the diet-shift effect (i.e., spending on fish grow faster than income), the World Bank's database suggests that when per-capita income in Egypt increases by $1 \%$, the spending on fish will increase by around $1.5 \%$, i.e., an additional of $0.5 \%$. This is a relatively high growth rate given the fact that per-capita fish consumption in Egypt in 2016 is only marginally below that of European countries that have 10-fold income. Put it differently, if the World Bank's assumption about the diet-shift unfolded true by 2030, each Egyptian citizen would consume 1.5 times more in quantity compared to a European neighbour while earning only $14 \%$ of the income. For this reason, we adjust this assumption downward by assuming that the spending on fish in Egypt would increase by the same rate as the per-capita income; and with this assumption, the fish consumption of Egypt by 2030 would be comparable to the current level of the European countries.

\subsection{Scenarios}

To identify the scenarios of interest, a workshop was organized with participants coming from various stakeholder groups, including: government, NGO, academia, research institutes, and private sector. A twoday technical workshop was conducted in Cairo, where more than 20 specialists from different fields of expertise, covering fisheries, aquaculture, trade and economics, and food security. The participants brought a diverse experience and expertise to the review of current status, and scenario setting and future visioning process.

The workshop participants were asked to discuss barriers to the growth of Egypt's fishery sector until 2030, together with the channels of impact. To facilitate the discussion, the participants were preprovided with a list of factors, and they could add their own assessments. The pre-provided factors are those that have been mentioned in the literature, including conditions of input markets, trade policies, infrastructure capacity, environmental constraints, and infectious disease outbreaks $[29,39]$.

The outcome of the workshop was practical as expected. The participants first agreed with all pre-provided factors except for infrastructure capacity as they did not consider this factor as a key obstacle of the fishery sector. More interestingly, all participants from the business sector indicated that increases in labour cost, a factor not in the preprovided list, would have a significant impact on the fishery sector. This point was admitted by all other participants because the rising wage rate was already squeezing labour-intensive production types. The participants suggested that increases in labour costs should be taken into account in all scenarios. Some participants also mentioned nonquantifiable factors such as institutional obstacles or red-tape in the administrative system.

We combined the outcome of the workshop with the foresight model to analyse several highlighted scenarios for Egypt's fishery sector. In all considered scenarios, the wage rate is assumed to increase at the same rate as the per-capita income of Egypt, as suggested by the workshop participants. In the first scenario, except for the wage rate, other factors such as environmental policy and input markets are assumed to remain similar to the base year, so for short, we term it 'the baseline scenario'. This baseline scenario is a common benchmark of alternative scenarios considered in the paper, not necessarily the most likely outcome in the future. The objective of this first scenario was to shed light on the fundamental barriers that would arise if Egypt's fishery sector was to develop in the current trend and serve as a comparison benchmark for the remaining alternative scenarios.

The remaining scenarios were grouped into two broad categories. The first category included scenarios about the aquaculture input markets, namely, what would happen if there were increases in the price of feed, seed, and water. The second category focused on the impact of taxes and disease outbreaks. Each category included several some scenarios which were compared to the outcome of the baseline scenario to highlight the impact of individual factors.

\section{Results}

\subsection{The baseline scenario}

We solved the model under the baseline assumption and summarized the projection of fish production in Fig. 1. As shown in the left panel, tilapia production in Egypt would remain the largest component, accounting for $63 \%-66 \%$ of the total output. The shares of mullets, carps and other species would be similar at around $10 \%-12 \%$, though specific numbers slightly vary across time. The total fish output is projected to increase from 1.7 million tons in 2016 to more than 2.4 million tons in 2030 , i.e., by approximately $42 \%$ over the projection period, or an average of $2.4 \%$ a year.

The increase in the total output is driven by the expansion of the aquaculture sector, as shown in the right panel. The aquaculture output would increase by $52 \%$, from 1.37 million tons in 2016-2.09 million tons in 2030 , or in other words, roughly $3 \%$ a year - which is slightly above the GDP growth rate. Semi-intensive aquaculture would remain the main production type, accounting for $85 \%-88 \%$ of the aquaculture output. The intensive production type has the fastest growth, around six times between 2016 and 2030, though its share in the total production remains relatively small. Cage aquaculture - the second largest aquaculture production type - would marginally grow by $6 \%$ over the 2016-2030 period, i.e., an average growth rate of only $0.4 \%$ a year, and its share in the total aquaculture output would decline from around $13-9 \%$. Rice fields ( rice-fish polyculture) in 2030 would remain more or less similar to 2016 level, so its share in the aquaculture output would fall because of the expansion of the other production types.

The changes in the composition of aquaculture, with increasing shares of intensive and semi-intensive production and declining shares of cages and rice-fields, are mainly driven by the increases in labour cost. As the wage rate rises, labour-intensive production types will have their profitability decline in relation to other sectors, which shrinks their relative shares in the total output. From the data in Table 1, it can be shown that cage and rice-fish system are more labour-intensive than intensive and semi-intensive aquaculture. In particular, the shares of labour in the total cost are $6 \%$ and $60 \%$ for cages and rice-fish systems, respectively, while the numbers are less than $1 \%$ for both intensive and semi-intensive. This fact represents an underlying trend where aquaculture types that are using relatively less labour will play more important roles in satisfying the increasing demand for fish.

However, the rapid growth of less labour-intensive production types would substantially increase non-labour inputs, another pressure on the growth of the fishery sector. This pressure is reflected in the left panel of Fig. 2, which shows the dynamics of the requirements for aquaculture inputs. As the inputs have different measurement units, we use input quantity indices in the figure to be able to compare their growth rates (with year 2016 is normalised to 100\%). Here, the requirement for fresh water would increase to round by around 1.6 times by 2030 , followed by seed and feed, for which the quantity would increase to more than 1.5 times during the same period. The requirement for fuel would also increase to more than 1.4 times. The requirement for labour would grow by only around 5\% over the $2016-2030$ period, the lowest growth rate, due to the shrinking of labour-intensive production types.

To provide further insights into the pressure caused by input requirements, we use the survey data about water use in aquaculture summarised by Yacout et al. [48] and Henriksson et al. [19] to estimate the quantity of fresh water in this baseline scenario. The estimated results suggest that by 2030, Egypt's aquaculture sector alone would require approximately 10.2 billion cubic metres of freshwater. This is a sixth of the water volume that the Nile River, the primary source of 

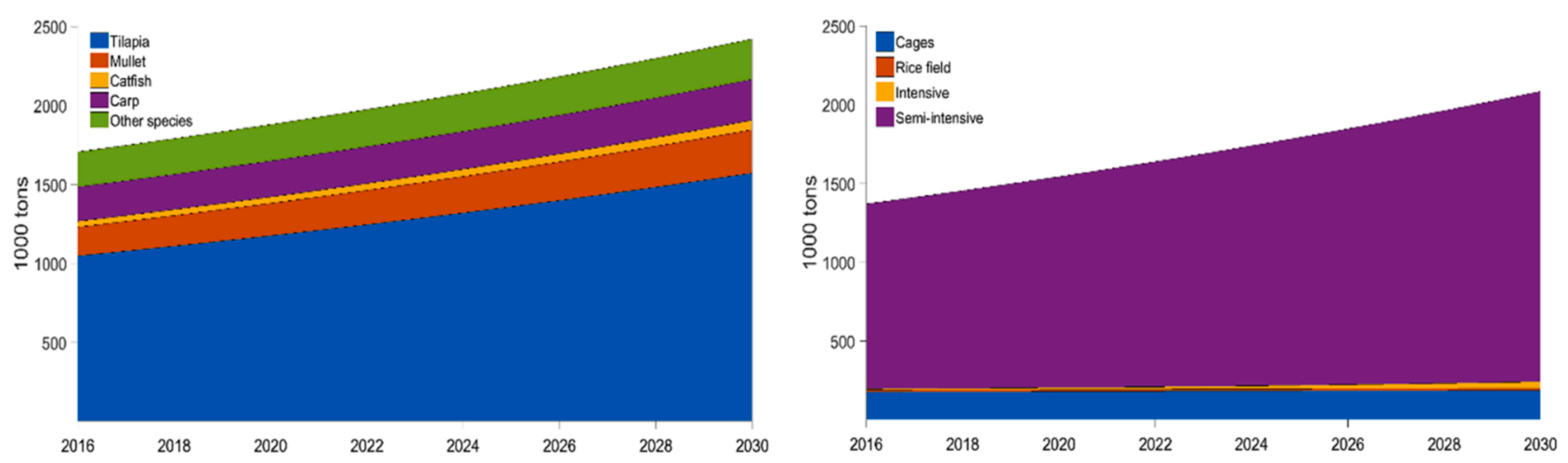

Fig. 1. Total production (left) and aquaculture output (right) of Egypt in the baseline scenario.
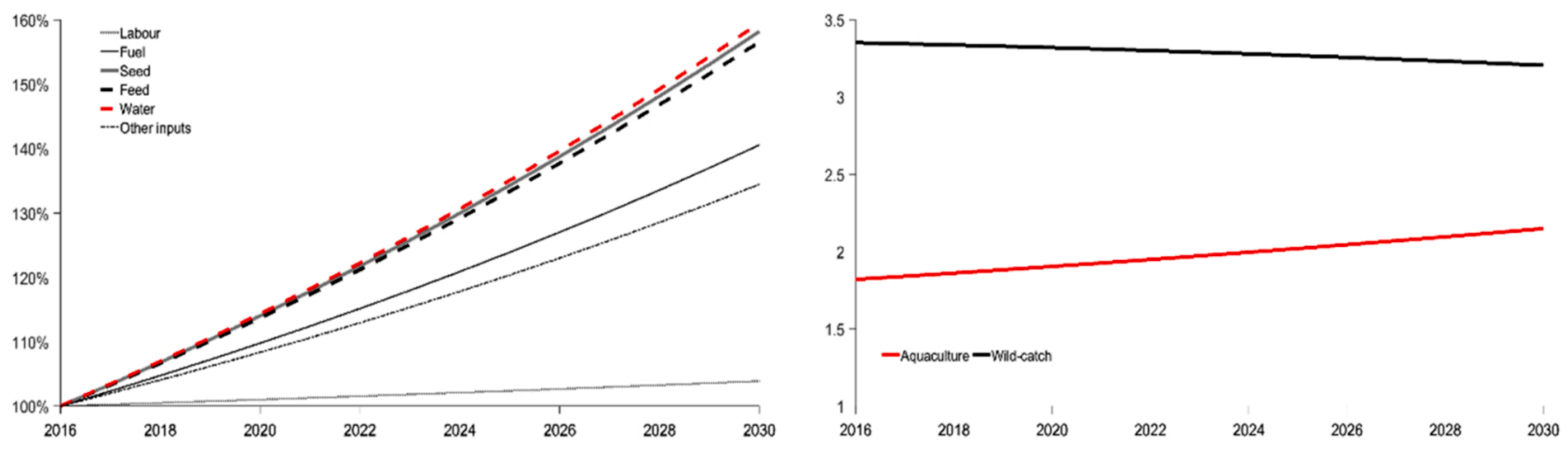

Fig. 2. Projected demand for inputs (left) and profitability (right) of Egypt's fishery sector.

freshwater, can potentially supply to Egypt. In addition, input-supply industries would also require a significant amount of water to produce feed and seed [48]. This scenario, if it unfolds, would pose significant risks to both water security and environmental sustainability in Egypt unless the aquaculture wastewater was used for other farming activities.

The foresight model also allows us to project the profitability for each sector in terms of benefit-cost ratios (BCR). The profitability of aquaculture and wild-catch sectors is summarised in the right panel of Fig. 2. The BCR of wild-catch would remain higher than that of the aquaculture sector though slightly declining due to the increases in the labour cost. This result suggests that incentives for overfishing might not be rising in the baseline scenario, though it does not necessarily imply that regulatory measures already in place could be relaxed. In contrast, the average BCR of the aquaculture sector would increase even with a higher wage rate. This is because of the shift toward less-labour intensive production types. In addition, there would also be a steady increase in demand for fish as driven by the income and population growth, which would contribute to an increase in fish price, offsetting the rising wage rate, and thus increasing the profitability of the aquaculture sector.

The projected fish consumption and price dynamics are summarised in the left panel of Fig. 3. Fuelled by the income growth, per-capita fish consumption in Egypt would increase from $20.6 \mathrm{~kg}$ /year in 2016 to over $23 \mathrm{~kg} /$ year in 2030, roughly similar to the current consumption level in European neighbours. The Fisher index shows that the overall fish price in Egypt would increase by nearly 27\% over the $2016-2030$ period, slightly more than the forecasted $25 \%$ increase in the average world price of fish. Within the consumption basket, the group 'other' which mainly includes sea bream, sea bass, meagre, shrimp, mackerel, and herring, has the fastest growing price of $28.4 \%$, while Tilapia - the group with the largest share- has its price increased by $26 \%$, the lowest increase among the five species.

As fish price increases in the domestic market more than in the world market, the net import of fish would widen, as shown in the right panel
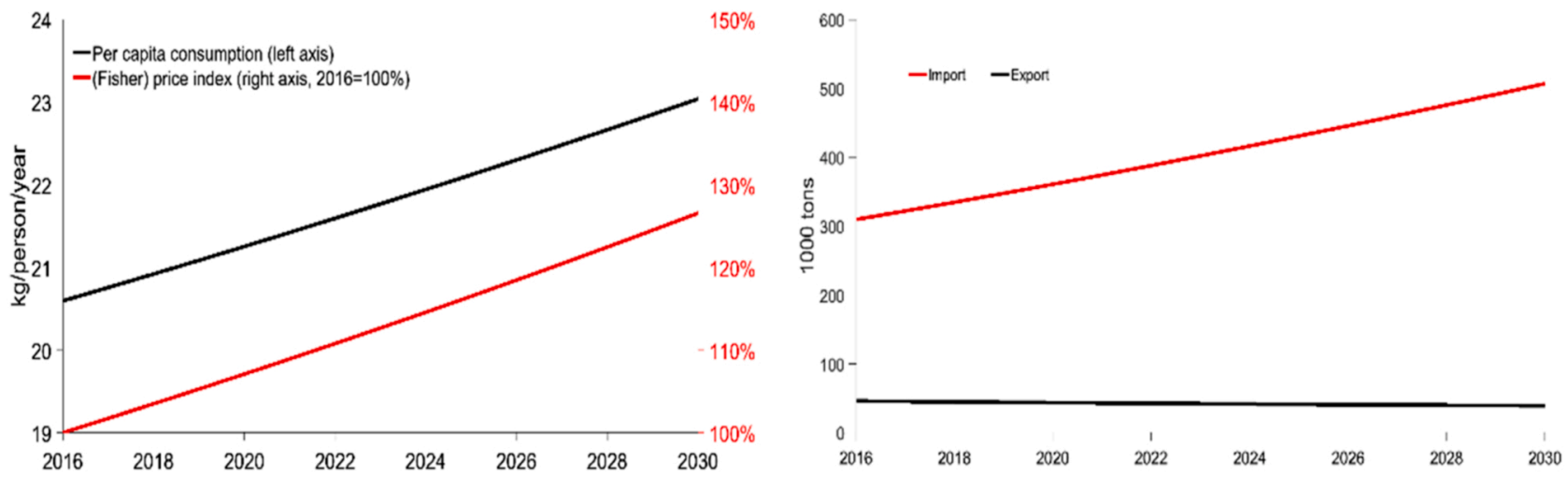

Fig. 3. Projected consumption and price (left) and international trade (right) of fish in Egypt. 
of Fig. 3. Fish export would marginally decline while imports would increase to more than 0.5 million tons by 2030. In 2016, Egypt imported 0.31 million tons of fish which mainly included products under the 'other species' group such as mackerel, herring, pangasius, tuna, sardine, and shrimp. The increase in imports reflects the impact of rising income on demand for species that are not produced in Egypt. In Section 3.4 , we analyse the scenarios where the government attempts to intervene on the import and export activities by imposing taxes.

\subsection{Feed and seed}

In this group of scenarios, we project the impact of an increase in the prices of the feed and seed and analyse how technological progress could improve the situation. In short, we use the label 'HiPrFeedSeed' for a scenario where the price of feed and seed is assumed to increase by $25 \%$ by 2030 and 'TechFeedSeed' for another scenario where technological progress helps reduce the requirement of feed and seed to produce a ton of fish reduced by $1 \%$ a year. The results of these scenarios, together with the baseline outcome, are summarised in Table 3, which reports the projected growth, rounded to the nearest percentage point, over the 2016-2030 period. The first three indicators are total consumption, total production, and net import, followed by the changes in the requirement for feed, seed and water as well as the overall fish price index and the profitability of the wild-catch sector.

The projection outcomes suggest that the growth of total fish consumption driven by demographic and economic growth would remain similar in the considered scenarios while other indicators will vary. In the 'HiPrFeedSeed' scenario, where feed and seed become more expensive, total production would grow by only $15 \%$ during the 2016-2030 period because aquaculture profit shrinks, a relatively slower growth compared to $42 \%$ in the baseline scenario. The shortfall caused by the reduction in domestic supply would be met by faster growth of net import, from $77 \%$ to $225 \%$. Technological progress, if capable of improving the efficiency of input use, would partially offset the impact of the rising input prices on total production with a growth of $34 \%$ over the $2016-2030$ period and a $122 \%$ growth of net import.

The rising prices of feed and seed would also significantly reduce the growth of input requirement, from around $57 \%-60 \%$ in the baseline scenario to $20 \%-21 \%$. However, as production was far outpaced by demand, the domestic fish price would rise faster with a growth rate of $35 \%$ over the projection period as compared to $27 \%$ in the baseline. A side effect of a higher domestic fish price is that the wild-catch sector( which does not suffer from the rising prices of feed and seed) and the rice-fish polyculture which have a lower share of labour in their cost structure compared to other aquaculture types, would benefit from a higher rate of return. This situation might provide incentives for expanding the marine catch and thus put more pressure on regulatory authority for further measures to maintain the sustainability of marine resources.

\subsection{Water prices}

This group of scenarios focuses on water pricing and the impact of

Table 3

Feed and seed results.

\begin{tabular}{lllll}
\hline & Parameter & Baseline & 5\% loss & 10\% loss \\
\hline \multirow{2}{*}{ Agg. Indicators } & Total Consumption (\%) & 47 & 46 & 46 \\
& Total Production (\%) & 42 & 35 & 28 \\
& Net import (\%) & 77 & 119 & 161 \\
Input Req. & Seed (\%) & 58 & 56 & 54 \\
& Feed (\%) & 57 & 55 & 53 \\
\multirow{5}{*}{ Price \& Profit } & Water (\%) & 60 & 57 & 55 \\
& Price index (\%) & 27 & 29 & 31 \\
& Catch BCR (\%) & -4 & -2 & 0 \\
\hline
\end{tabular}

*** All values represent percent change. technological progress on water efficiency. In particular, we analyse what would be the outcome if the government imposes a price of, say, $\$ 0.05 / \mathrm{m} 3$ on aquaculture water input to restrict the use of fresh water and if the requirement of inputs, including water, to produce a ton of fish could be reduced by $1 \%$ a year. These two scenarios are labelled as 'HiPrWater' and 'TechProg', respectively, and their outcomes are summarised in Table 4 in comparison to the baseline scenario.

The results in Table 4 suggest that while the growth of total fish consumption would still remain more or less similar to the baseline scenario, water pricing would significantly slow down the growth of the aquaculture sector and increase the net import of fish. Water pricing would affect semi-intensive and intensive aquaculture, the fastest growing sectors in the baseline scenario because these are the only aquaculture types that use water as an input. This 'crowd-out' impact would also slow down the demand for seed, feed and water, from nearly $60 \%$ in the baseline scenario to around $16 \%-17 \%$ during the projection period.

The water pricing policy would significantly increase the overall price of fish via the production cost, especially that of semi-intensive aquaculture, which has the largest share in fish production. The increases in fish price would benefit the wild-catch sector, prompting measures to avoid overfishing in marine resources. Similar to the case where the costs of seed and seed increase ('HiPrFeedSeed'), technological progress which helps improve input-use efficiency would help partially offset the crowd-out impact.

\subsection{Import and export regulation}

The projection outcome for the impact of taxes is summarised in Table 5. In the scenario labelled 'ImpTax', the government imposes a $10 \%$ import tax rate on all imported fish. In the 'ExpTax' scenario, it is assumed that the export tax rate would be raised by ten percentage points. For comparison purposes, Table 3 also includes the outcome of the baseline scenario.

With the import tax, the net import would reverse, as expected, from a growth of $77 \%$ in the baseline scenario to a decline of $28 \%$ over the 2016-2030 period. However, the tax would increase the overall price of fish that would slow down the growth of fish consumption. Domestic fish production would be protected from the competition of imported products and benefit from the import tax, but a faster growth of domestic production would also increase the requirement for inputs. The rate of return of the wild-catch sector would still decline, though by less than in the baseline scenario.

In the 'ExpTax' scenario, export would be restricted, so more fish would be retained in the domestic market, and the growth of domestic fish price would be slowed down. However, this impact on price would be modest, with the price growth declining from $27 \%$ in the baseline scenario to $26 \%$ under the export tax. Both total consumption and production would remain more or less similar to the baseline scenario, but net import would widen because of the weakened export. The wildcatch sector, which produces high-quality fish for export, would probably suffer most from the export tax with a decline in the rate of return.

Table 4

Water pricing results.

\begin{tabular}{lllll}
\hline & Parameter & Baseline & HiPrWater & TechProg \\
\hline \multirow{2}{*}{ Agg. Indicators } & Total Consumption (\%) & 47 & 48 & 46 \\
& Total Production (\%) & 42 & 13 & 31 \\
& Net import (\%) & 77 & 276 & 141 \\
Input Req. & Seed (\%) & 58 & 16 & 22 \\
& Feed (\%) & 57 & 17 & 22 \\
\multirow{5}{*}{ Price \& Profit } & Water (\%) & 60 & 16 & 22 \\
& Price index (\%) & 27 & 36 & 30 \\
& Catch BCR (\%) & -4 & 5 & -1 \\
\hline
\end{tabular}

$* * *$ All values represent percent change. 
Table 5

Import and Export Regulation Results.

\begin{tabular}{lllll}
\hline & Parameter & Baseline & ImpTax & ExpTax \\
\hline \multirow{2}{*}{ Agg. Indicators } & Total Consumption (\%) & 47 & 38 & 46 \\
& Total Production (\%) & 42 & 48 & 41 \\
& Net import (\%) & 77 & -28 & 80 \\
Input Req. & Seed (\%) & 58 & 66 & 57 \\
& Feed (\%) & 57 & 64 & 56 \\
\multirow{5}{*}{ Price \& Profit } & Water (\%) & 60 & 68 & 59 \\
& Price index (\%) & 27 & 30 & 26 \\
& Catch BCR (\%) & -4 & -3 & -5 \\
\hline
\end{tabular}

$* * *$ All values represent percent change.

\subsection{Disease outbreak}

The projection outcome for the two scenarios with disease outbreaks is reported in Table 6 . In both scenarios, the growth of total consumption - as driven by population and economic development - would be similar to the baseline, but the production sector would slow down considerably. The shortfall between total consumption and total production would be met by a significantly widening net import of fish. When aquaculture is hit by infectious diseases, the fish price would increase faster, and the rate of return of the wild-catch sector would not decline as much as under the BAU assumptions.

\section{Discussion}

Our analysis provides some insights into the specific obstacles to the sustainable growth of Egypt's fishery sector in the near future. The scenarios analysed here are based upon the concerns and expertise of relevant stakeholders within the country, and as such, our results are pertinent to policymakers and stakeholders concerning sustainable fisheries and aquaculture development for food and nutrition security in Egypt. We provide a tool that summarizes the effects of these relevant scenarios on fish consumption, trade, and prices. These are key indicators that provide an overall outlook of the fishery sector and food security in Egypt.

Traditional diets in Egypt prioritise fish products, making up 38\% of total animal protein consumed. The per capita consumption of fish in the country has grown considerably over the past two decades and will continue to increase in the future. The results of our model indicate that per capita consumption is projected to increase from $20.6 \mathrm{~kg}$ in 2016 to $23 \mathrm{~kg}$ in 2030, an increase of almost $3 \mathrm{~kg}$ per person per year. These increases are driven by a combination of population growth, economic growth, and a growing consumers' desire to consume nutritious and healthy foods. Due to the stagnation of capture fisheries, aquaculture will continue to be the main contributor to the domestic aquatic food supply. According to our model, aquaculture production will grow between $14 \%$ and $46 \%$, depending on the scenario being considered. Upward pressure from limited input supply in aquaculture is also predicted to increase the price of fish considerably by as much as $36 \%$ by 2030 .

Aquaculture inputs in Egypt, including feed, seed, labour, and water, were identified as one of the major threats to aquaculture production.

Table 6

Disease outbreak results.

\begin{tabular}{lllll}
\hline & Parameter & baseline & $\mathbf{5 \%}$ loss & $\mathbf{1 0 \%}$ loss \\
\hline \multirow{2}{*}{ Agg. Indicators } & Total Consumption (\%) & 47 & 46 & 46 \\
& Total Production (\%) & 42 & 35 & 28 \\
& Net import (\%) & 77 & 119 & 161 \\
Input Req. & Seed (\%) & 58 & 56 & 54 \\
& Feed (\%) & 57 & 55 & 53 \\
\multirow{5}{*}{ Price \& Profit } & Water (\%) & 60 & 57 & 55 \\
& Price index (\%) & 27 & 29 & 31 \\
& Catch BCR (\%) & -4 & -2 & 0 \\
\hline
\end{tabular}

*** All values represent percent change.
Our model highlights the importance of these factors when considering the future of the sector. Increasing feed and seed prices in Egypt can be expected to limit increases in domestic production to $15 \%$, a substantial decrease when compared to the baseline scenario where production increases by $42 \%$. Limited production growth due to high feed and seed prices will increase fish imports into Egypt by $255 \%$, increasing the share of imported fish consumed domestically and increasing the price of fish by almost $10 \%$ more than the baseline scenario. This drastic increase in fish imports has consequences in terms of food security, job creation and income generation. Possible technological efficiency gains may provide a buffer for the effects summarized, limiting imports to $122 \%$ while reducing production losses. Egypt has a very competitive market for feed with over 100 companies providing products, however, these products depend on imported raw materials, which leaves prices vulnerable to international dynamics. These results highlight the necessity of policies that can curb potential input price increases in order to protect food and job security, as well as policies that may incentivize innovation in aquaculture production.

Another key input for freshwater aquaculture in Egypt is water, a natural resource that is characterized by growing scarcity in northern African countries, including Egypt, due to global climate change impacts $[21,35]$. In fact, the water supply in Egypt is expected to drop from 53 to $50 \mathrm{BCM}$ in 2025, while the population will increase by approximately 20 million [28]. Furthermore, aquaculture is the second user of freshwater in the agricultural system, meaning that water used for aquaculture depends on agricultural runoff from cropland. As water scarcity increases, the agricultural industry has been focussing heavily on maximizing the efficiency of their agricultural systems, as is outlined by the National Water Policy [18]. Increasing efficiency in agriculture production also means less runoff to be used by the aquaculture sector, creating a possible acute water shortage for freshwater aquaculture. Our model shows that water availability will be a critical issue for Egyptian aquaculture. Our model predicts that issues of water availability will drastically decrease production growth and increase imports, causing the price of fish to inflate relative to the baseline scenarios. The aquaculture composition and production systems may also be altered by water shortages or prices. There might be bright prospects for more water efficient systems like in-pond raceways and recirculating aquaculture systems (RAS) to increase production with less water as a result of water shortages. Intensive and semi-intensive aquaculture, which make up most of the production, requires less labour than alternatives, but they are heavily reliant on water and energy inputs. This fact puts the aquaculture sector at risk of being vulnerable to water shortages and possibly having to resort to more labour-intensive methods, which will subsequently significantly increase fish prices. This is especially concerning due to the projected increased reliance on less labour-intensive aquaculture methods due to rising wage rates.

In addition to the effects of water shortages on aquaculture, it has also been reported that agricultural runoff water is a potential source of bio-chemical contaminants which negatively affect fish development [8]. Water pollution can also be related to fish disease, which is another threat to the aquaculture sector in Egypt. Our analysis discussed the implications of fish disease that limited production by $5 \%$ and $10 \%$. In these scenarios, we again see adverse effects on production, which leads to increased imports, though not drastically in both cases.

All the mentioned scenarios above rely on increasing imports and fish prices to offset rising costs. While imports may be controlled by an import tax, this option would potentially have drastic negative impacts on fish consumption and prices. In addition, external impacts on capture fisheries should also be considered. For instance, a higher fish price may increase the risk of overexploiting marine resources due to the increased profit incentives. This channel should not be overlooked as Egypt's capture fisheries have been fully exploited for the last couple of decades, and increased activity in this sector could potentially have long-lasting environmental effects. Our analysis demonstrates that these risks may be mitigated via technological advancements. 


\section{Conclusion}

We have shown that fish demand in Egypt will increase steadily, driven primarily by population growth and economic growth. Based on the options and concerns of relevant stakeholders, our analysis shows that constraints to the sustainable development of aquaculture in Egypt need to be managed by decision-makers. Egypt faces substantial challenges pertaining to increasing aquaculture input prices, water scarcity, trade policy, and fish disease outbreaks. The most pressing of these issues are aquaculture input and freshwater availability. These constraints will negatively affect production and drastically increase prices and import quantities. Attempting to mitigate these constraints by implementing an import tax would have further negative effects by significantly inflating domestic prices and severely limiting supply. However, these negative effects can partially be mitigated through technological progress in both input and water-use efficiency. The economics of application of these new technologies deserve further analysis.

Understanding these obstacles is necessary to sustain current consumption levels and ensure food security in Egypt. Fish is one of the primary sources of animal protein and micronutrients for Egyptian consumers and must be taken seriously. Due to the stagnation of capture fisheries, sustainable intensification of aquaculture must be considered the only plausible avenue of fish supply growth in the future. Our analysis provides a tool for policymakers in Egypt, helping them understand the implications of relevant challenges that the country's fishery sector is currently facing. This will guide the direction of future policy, which will ensure that the worst outcomes are avoided.

\section{CRediT authorship contribution statement}

All authors collectively contributed to original paper writing, revised the paper and approved its resubmission.

\section{Declaration of Competing Interest}

The authors declare that they have no known competing financial interests or personal relationships that could have appeared to influence the work reported in this paper.

\section{Data availability}

Data will be made available on request.

\section{Acknowledgements}

This research is a contribution to the CGIAR Research Program on Fish Agrifood Systems (FISH) led by WorldFish. Funding support for this work was provided by CGIAR Trust Fund donors. We would like to thank all funders who support this research through their contributions to the CGIAR Trust Fund: https://www.cgiar.org/funders/. The authors also highly acknowledge the partnership and contributions of a wide range of public, private, community and civil society members and organizations in Egypt to the research.

\section{Appendix A. Supporting information}

Supplementary data associated with this article can be found in the online version at doi:10.1016/j.marpol.2022.105333.

\section{References}

[1] S. Aiyar, R.A. Duval, D. Puy, Y. Wu, L. Zhang, Growth slowdowns and the middleincome trap, IMF Work. Pap. Volume 2013 (2013), https://doi.org/10.5089/ 9781484330647.001.

[2] P.S. Armington, A theory of demand for products distinguished by place of production, Staff Pap. 16 (1969) 159-178.
[3] C. Béné, R. Arthur, H. Norbury, E.H. Allison, M. Beveridge, S. Bush, M. Williams, Contribution of fisheries and aquaculture to food security and poverty reduction: assessing the current evidence, World Dev. 79 (2016) 177-196, https://doi.org/ 10.1016/j.worlddev.2015.11.007.

[4] C.Y. Chan, N. Tran, S. Pethiyagoda, C.C. Crissman, T.B. Sulser, M.J. Phillips, Prospects and challenges of fish for food security in Africa, Glob. Food Secur. 20 (2019) 17-25, https://doi.org/10.1016/j.gfs.2018.12.002.

[5] C. Dawkins, T. Srinivasan, J. Whalley, Calibration, in: J.J. Heckman, E.E. Leamer (Eds.), Handbook of Econometrics, Elsevier, 2001.

[6] M.M. Dey, R.M. Briones, M. Ahmed, Disaggregated analysis of fish supply, demand, and trade in Asia: baseline model and estimation strategy, Aquac. Econ. Manag. 9 (1-2) (2005) 113-139, https://doi.org/10.1080/13657300590961555.

[7] El-Naggar, G., Nasr-Alla, A., and Kareem, R.O., 2008, Economic Analysis of Fish Farming in Behera Governorate of Egypt. In: Elghobashy, H., Fitzsimmons, K., Diab, A.S. (eds.) Proceedings of 8th International Symposium on Tilapia in Aquaculture, Cairo, Egypt, 12-14 Oct 2008. Vol. 1. "From the pharaohs to the future" DOI: 10.13140/2.1.4794.5927.

[8] M. Eltholth, K. Fornace, D. Grace, J. Rushton, B. Häsler, Characterisation of production, marketing and consumption patterns of farmed tilapia in the Nile Delta of Egypt, Food Policy 51 (2015) 131-143, https://doi.org/10.1016/j. foodpol.2015.01.002.

[9] FAO, 2016, The State of World Fisheries and Aquaculture - Contributing to Food Security and Nutrition for All. Rome.

[10] FAO. 2018, The State of World Fisheries and Aquaculture 2018 - Meeting the sustainable development goals. Rome.

[11] FAO. 2020, The State of World Fisheries and Aquaculture 2020. Sustainability in action. Rome. https://doi.org/10.4060/ca9229en.

[12] I.H. Feidi, Impact of International Fish Trade on Food Security in Egypt. FAO Fisheries Report No 708 Expert Consultation on Interntional Fish Trade and Food Security, FAO, Casablanca, Morocco, 2003.

[13] GAFRD (General Authority for Fisheries Resources Development), 2001, Fisheries Statistics Year Book 2016. Cairo, GAFRD.

[14] GAFRD (General Authority for Fisheries Resources Development), 2019, Fisheries Statistics Year Book 2016. Cairo, GAFRD.

[15] GAFRD (General Authority for Fisheries Resources Development), 2020, Fisheries Statistics Year Book 2016. Cairo, GAFRD.

[16] GAFRD (General Authority for Fisheries Resources Development), 2021, Fisheries Statistics Year Book 2016. Cairo, GAFRD.

[17] I. Gill, H. Kharas, An East Asian Renaissance: Ideas for Economic Growth, World Bank, Washington, DC, 2007. License: CC BY 3.0 IGO.

[18] W. Hamza, S. Mason, Water availability and food security challenges in Egypt. Proceedings International Forum on Food Security Under Water Scarfcity in the Middle East, Problems and Solutions. Como, Italy, 2004, pp. 24-27.

[19] P.J. Henriksson, M. Dickson, A.N. Allah, D. Al-Kenawy, M. Phillips, Benchmarking the environmental performance of best management practice and genetic improvements in Egyptian aquaculture using life cycle assessment, Aquaculture 468 (2017) 53-59, https://doi.org/10.1016/j.aquaculture.2016.09.051.

[20] K. Hua, J.M. Cobcroft, A. Cole, K. Condon, D.R. Jerry, A. Mangott, J.M. Strugnell, The future of aquatic protein: implications for protein sources in aquaculture diets, One Earth 1 (3) (2019) 316-329, https://doi.org/10.1016/j.oneear.2019.10.018.

[21] IPCC, Climate Change 2007: impacts, adaptation and vulnerability, in: M. L. Change, O.F. Parry, J.P. Canziani, P.J. Palutikof, van der Linden, C.E. Hanson (Eds.), Contribution of Working Group II to the Fourth Assessment Report of the Intergovernmental Panel on Climate, Cambridge University Press, Cambridge, UK, 2007, p. 976

[22] M.D. Jansen, H.T. Dong, C.V. Mohan, Tilapia lake virus: a threat to the global tilapia industry? Rev. Aquac. 11 (3) (2019) 725-739, https://doi.org/10.1111/ raq.12254.

[23] L.J. Journo, D.G. Salmon, Gain report: the state of aquaculture in Egypt, USDA (2015) 1-13.

[24] M. Kobayashi, S. Msangi, M. Batka, S. Vannuccini, M.M. Dey, J.L. Anderson, Fish to 2030: the role and opportunity for aquaculture, Aquac. Econ. Manag. 19 (3) (2015) 282-300, https://doi.org/10.1080/13657305.2015.994240.

[25] W. Kong, S. Huang, Z. Yang, F. Shi, Y. Feng, Z. Khatoon, Fish feed quality is a key factor in impacting aquaculture water environment: evidence from incubator Experiments, Sci. Rep. 10 (1) (2020) 1-15, https://doi.org/10.1038/s41598-01957063-w.

[26] M. Krkošek, Population biology of infectious diseases shared by wild and farmed fish, Can. J. Fish. Aquat. Sci. 74 (4) (2017) 620-628, https://doi.org/10.1139/ cjfas-2016-0379.

[27] K.D. Lafferty, C.D. Harvell, J.M. Conrad, C.S. Friedman, M.L. Kent, A.M. Kuris, S. M. Saksida, Infectious diseases affect marine fisheries and aquaculture economics, Annu. Rev. Mar. Sci. 7 (2015) 471-496, https://doi.org/10.1146/annurev-marine010814-015646.

[28] P. Luo, Y. Sun, S. Wang, S. Wang, J. Lyu, M. Zhou, D. Nover, Historical assessment and future sustainability challenges of Egyptian water resources management, J. Clean. Prod. 263 (2020), 121154, https://doi.org/10.1016/j. jclepro.2020.121154.

[29] G. Macfadyen, A.M. Nasr-Alla, D. Al-Kenawy, M. Fathi, H. Hebicha, A.M. Diab, G. El-Naggar, Value-chain analysis-An assessment methodology to estimate Egyptian aquaculture sector performance, Aquaculture 362 (2012) 18-27, https:// doi.org/10.1016/j.aquaculture.2012.05.042.

[30] S. Murphy, H. Charo-Karisa, S. Rajaratnam, S.M. Cole, C. McDougall, A.M. Nasr Allah, N. Ibrahim, Selective breeding trait preferences for farmed tilapia among low-income women and men consumers in Egypt: Implications for pro-poor and 
gender-responsive fish breeding programmes, Aquaculture 525 (2020), 735042, https://doi.org/10.1016/j.aquaculture.2020.735042.

[31] Nasr-Alla, A., Macfadyen, G., Dickson, M., Al-Kenawy, D., Fathi, M., \& El-Naggar, G. (2012). Value chain analysis of the Egyptian aquaculture sector. In Proceedings of IIFET Conference in Dar El Salam, Tanzania (Vol. 16)., https://doi.org/ 10.13140/2.1.3709.2808.

[32] A. Nasr-Allah, A. Gasparatos, A. Karanja, E.B. Dompreh, S. Murphy, C. M. Rossignoli, H. Charo-Karisa, Employment generation in the Egyptian aquaculture value chain: implications for meeting the sustainable development goals (SDGs), Aquaculture 520 (2020), 734940, https://doi.org/10.1016/j. aquaculture.2020.734940.

[33] R.L. Naylor, A. Kishore, U.R. Sumaila, I. Issifu, B.P. Hunter, B. Belton, B. Crona, Blue food demand across geographic and temporal scales, Nat. Commun. 12 (1) (2021) 1-14, https://doi.org/10.1038/s41467-021-25516-4.

[34] K. Obiero, P. Meulenbroek, S. Drexler, A. Dagne, P. Akoll, R. Odong, B. KaundaArara, $\mathrm{H}$. Waidbacher, The contribution of fish to food and nutrition security in Eastern Africa: Emerging trends and future outlooks, Sustainability 11 (6) (2019) 1636, https://doi.org/10.3390/su11061636.

[35] M.E.D.M. Omar, A.M.A. Moussa, R. Hinkelmann, Impacts of climate change on water quantity, water salinity, food security, and socioeconomy in Egypt, Water Sci. Eng. 14 (1) (2021) 17-27, https://doi.org/10.1016/j.wse.2020.08.001.

[36] Robinson, S., 2015, The International Model for Policy Analysis of Agricultural Commodities and Trade (IMPACT): Model Description for Version 3. IFPRI Discussion Paper: International Food Policy Research Institute.

[37] M.W. Rosegrant, I.D. Team, International Model for Policy Analysis of Agricultura Commodities and Trade (IMPACT): Model Description. International Food Policy Research Institute, IFPRI, Washington, DC, 2012.

[38] M. Samy-Kamal, Outlook on the fisheries policy reform in Egypt and the draft of the new fisheries law, Mar. Policy 120 (2020), 104136, https://doi.org/10.1016/j. marpol.2020.104136.

[39] M. Shaalan, M. El-Mahdy, M. Saleh, M. El-Matbouli, Aquaculture in Egypt: insights on the current trends and future perspectives for sustainable development, Rev.
Fish. Sci. Aquac. 26 (1) (2018) 99-110, https://doi.org/10.1080/ 23308249.2017.1358696.

[40] M. Sharaan, A. Negm, M. Iskander, K. Nadaoka, Questionnaire-based assessment of Mediterranean fishing ports, Nile Delta, Egypt, Mar. Policy 81 (2017) 98-108, https://doi.org/10.1016/j.marpol.2017.03.024.

[41] N.F. Soliman, D.M. Yacout, Aquaculture in Egypt: status, constraints and potentials, Aquac. Int. 24 (5) (2016) 1201-1227, https://doi.org/10.1007/s10499016-9989-9.

[42] S.H. Thilsted, A. Thorne-Lyman, P. Webb, J.R. Bogard, R. Subasinghe, M.J. Phillips, E.H. Allison, Sustaining healthy diets: The role of capture fisheries and aquaculture for improving nutrition in the post-2015 era, Food Policy 61 (2016) 126-131, https://doi.org/10.1016/j.foodpol.2016.02.005.

[43] K.A. Toufique, B. Belton, Is aquaculture pro-poor? Empirical evidence of impacts on fish consumption in Bangladesh, World Dev. 64 (2014) 609-620, https://doi. org/10.1016/j.worlddev.2014.06.035.

[44] N. Tran, U.P. Rodriguez, C.Y. Chan, M.J. Phillips, C.V. Mohan, P.J.G. Henriksson, S. Hall, Indonesian aquaculture futures: An analysis of fish supply and demand in Indonesia to 2030 and role of aquaculture using the AsiaFish model, Mar. Policy 79 (2017) 25-32, https://doi.org/10.1016/j.marpol.2017.02.002.

[45] N. Tran, L. Chu, C.Y. Chan, S. Genschick, M.J. Phillips, A.S. Kefi, Fish supply and demand for food security in Sub-Saharan Africa: An analysis of the Zambian fish sector, Mar. Policy 99 (2019) 343-350, https://doi.org/10.1016/j. marpol.2018.11.009.

[46] World Bank, Fish to 2030: Prospects for Fisheries and Aquaculture, World Bank, Washington DC, 2013.

[47] WHO, 2017, Worldwide trends in body-mass index, underweight. In: Overweight and Obesity from 1975 to 2016; a Pooled Analysis and Population-Based Measurement studies.

[48] D.M. Yacout, N.F. Soliman, M.M. Yacout, Comparative life cycle assessment (LCA) of Tilapia in two production systems: semi-intensive and intensive, Int. J. Life Cycle Assess. 21 (6) (2016) 806-819, https://doi.org/10.1007/s11367-016-1061-5. 